\title{
Diálogos com as artes visuais na casa de cultura popular de Caicó-RN
}

\author{
Jailson Valentim dos Santos \\ Custódio Jacinto de Medeiros
}

Universidade Federal da Paraíba

\section{Resumo}

Este artigo versa sobre a Casa de Cultura Popular de Caicó-RN. Nele, abordaremos práticas artísticas e culturais que são realizadas em suas dependências, com foco nas artes visuais. Evidenciamos o trabalho de dois artistas locais, a saber: Ronaldo Batista Sales (Magão) e Lydia Brasileira de Brito, pela destacada colaboração, pesquisas empíricas e provocações realizadas junto à sociedade caicoense, no que tange aos fazeres e apreciações artísticas. A partir de uma abordagem que envolve questões sobre arte e espaço cultural, refletiremos sobre a produção realizada no campo das artes visuais, procurando dialogar com artistas e estudiosos como Alfredo Bosi (1986), Allan Kaprow (2006). Jorge Larrosa Bondía (2002), Teixeira Coelho (1986) e Ernst Fischer (2002), pensando na implicação arte/vida. Entendemos que é fundamental a existência desse equipamento cultural para acolher as demandas que chegam da comunidade, contribuindo desde modo com a difusão e democratização da arte e da cultura no contexto local.

Palavras-chave: Arte e cultura. Espaço cultural. Seridó potiguar.

\section{Abstract}

This article is about the "Casa de Cultura Popular", from Caicó - RN. We discuss about the artistic and cultural practices that are done in that place, focusing the visual arts. We evidence the work by local artists: Ronaldo Batista Sales (Magão) e Lydia Brasileira de Brito, for their special contribuition, empirical research and provocations in Caicó society, related to artistic actions anda appreciations. With an approach that involves questions about cultural space and art, we reflect on the productions in visual arts, stablishing dialogue with artists and researchers such as Alfredo Bosi (1986), Allan Kaprow (2006), Jorge Larrosa Bondía (2002), Teixeira Coelho (1986) e Ernst Fischer (2002), thinking in art/life implication. We understand that is essential to the existence of this cultural equipment to host these necessities from the community, contributing to 
the difusion and democratization of culture and art in local contexto.

Keywords: Art and culture. Cultural space. RN Seridó.

A Casa de Cultura é uma forma privilegiada de ação cultural

Teixeira Coelho

\section{Primeiras palavras}

A Casa de Cultura Popular de Caicó-RN é um equipamento cultural do município que objetiva favorecer o contato com a expressão artística e cultural à população local, como também propiciar que artistas e agentes culturais desenvolvam suas atividades nesse campo do saber. A Casa é vinculada a Secretaria Extraordinária de Cultura/Governo do Estado do Rio Grande do Norte e a Fundação José Augusto, além de manter parceria com a Associação União do Sobrado e com o Ponto de Cultura Sobrando Arte no Sobrado. Ela ainda promove debates, cursos de formação e atividades ligadas à expressão artístico/cultural.

Deste modo, o artigo tem como objetivo refletir sobre as artes visuais que são produzidas e expostas nas suas dependências, evidenciando a produção de dois artistas: Lydia Brasileira de Brito (Caicó-RN, 1936 - ) e Ronaldo Batista Sales - Magão (Caicó-RN, 1958 - ), pelas destacadas colaborações, pesquisas e provocações realizadas no campo da Arte na região do Seridó-RN. Lydia e Magão são artistas que refletem o nosso tempo, em um território marcado pela aridez do solo e pela escassez de chuvas.

A arte e a cultura sempre foi assunto presente nas pautas de artistas, filósofos e pensadores outros. Na contemporaneidade, buscamos nos estudos de Alfredo Bosi (1986) suas reflexões sobre a arte. O estudioso paulista entende a arte dentro de uma trilogia que envolve o fazer, o conhecer e o exprimir. A noção de arte, em estreita relação com a vida, encontramos no artista norteamericano Allan Kaprow (2006). As ideias do Kaprow nos instigam a pensar que a vida se revela ao artista com potência e aberta à experiência. Já a noção de experiência é entendida pela perspectiva de Jorge Larrosa Bondía (2002), pois este estudioso espanhol evidencia que devemos ser sujeitos da experiência. Ernst Fischer (2002) com suas reflexões acerca da arte nos faz enxergar a necessidade da arte no contexto seridoense, enquanto que a contribuição de Teixeira Coelho (1986) foi no sentido de pensar as atividades que são realizadas na Casa de Cultura Popular de Caicó, uma vez que esta promove a Arte e atua no sentido de difundir e 
expandir suas ações culturais, valorizando o exercício da cidadania e a inclusão social. Essa instituição cultural funciona no Sobrado do Padre Brito Guerra e fica situada a Rua Padre João Maria, nº 134, no centro de Caicó.

\section{O Sobrado do Padre Guerra}

O Sobrado do Padre Guerra (Imagem 1) é uma construção histórica que foi erigida no ano de 1810/11, pelo Padre e Senador Francisco Brito Guerra, para lhe servir inicialmente como residência. Pela sua imponência e técnicas de construção avançada para a época, o edifício contribuiu para impulsionar o desenvolvimento urbano da cidade. A edificação também priorizou o ensino clássico de francês e latinidades, quando funcionou como segunda escola pública do Rio Grande do Norte, ainda no século dezenove. No período, era lugar de formalidades e disciplina e contribuía com a formação de uma elite pensante, instigada pelo padre e senador imperial. Este que ocupou postos decisivos na política e nas letras do Estado potiguar. Em 1994 o casarão assobradado foi adquirido pelo governo do Rio Grande do Norte e desde o dia 24 de julho de 2003 o Sobrado Padre Guerra funciona como sede da Casa de Cultura Popular de Caicó.

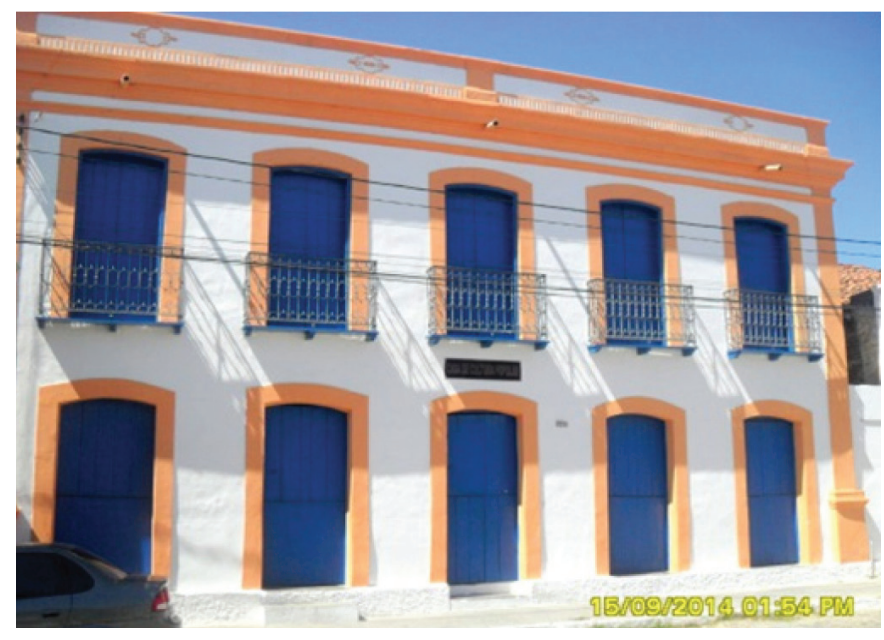

Figura 1

Fachada do Sobrado Padre Guerra Fonte: Acervo pessoal dos autores

\section{A Casa de Cultura Popular de Caicó}

A Casa de Cultura Popular de Caicó nasceu da reivindicação de artistas e de agentes culturais locais, feita ao poder público do Estado num momento em que existia políticas públicas favoráveis para isso, pois eles precisavam de um espaço para se reunir, produzir e promover a arte e a cultura no município. A Casa é um equipamento cultural 
público que oferece à comunidade caicoense a oportunidade de encontro com as expressões artísticas, enquanto promove os valores da cultura local. Um acervo permanente de objetos e obras de artistas populares constituem exposições periódicas (Imagem 2), que são abertas para um público diversificado, de segunda a sextas-feita, sempre em horário comercial. Sua antiga estrutura necessita de manutenção e reforma em suas acomodações, bem como de adaptações pertinentes ao abrigo de exposições e demais atividades artístico/expressivas, como por exemplo, de uma iluminação que corresponda aos desenhos ideais para exposição de obras de arte e bens simbólicos. A Casa dispõe de várias salas que são distribuídas em dois pavimentos e guarda um pequeno acervo de brinquedos populares antigos (Imagem 3) e de objetos utilitários que contam a história do povo do sertão do Seridó-RN (Imagem 4). Uma das salas abriga a Galeria de Cordelistas (Imagem 5), servindo também como local de encontro e convivência dos apreciadores da literatura de cordel, bem como para ministrar cursos dessa arte literária. Três de suas salas são destinadas a oficinas diversas e outra, com capacidade para acomodar até trinta pessoas, funciona como espaço para palestras. Essa instituição cultural possui ainda uma pequena biblioteca. No seu quintal (Imagem 6) acontecem shows diversos e espetáculos de teatro, enquanto suas paredes funcionam como suportes para intervenções artísticas.
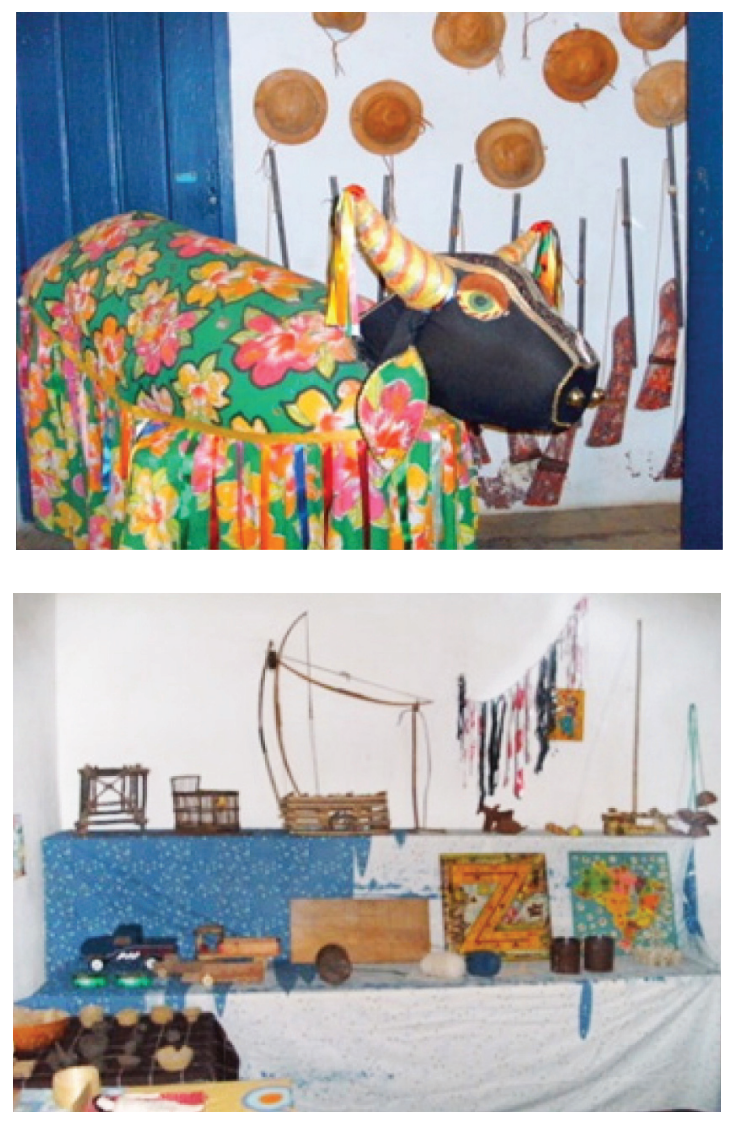

Imagem 2

Boi e objetos de uso cotidiano do sertanejo.

Fonte: Acervo pessoal dos autores

Imagem 3

Brinquedos populares em exposição.

Fonte: Acervo pessoal dos autores 


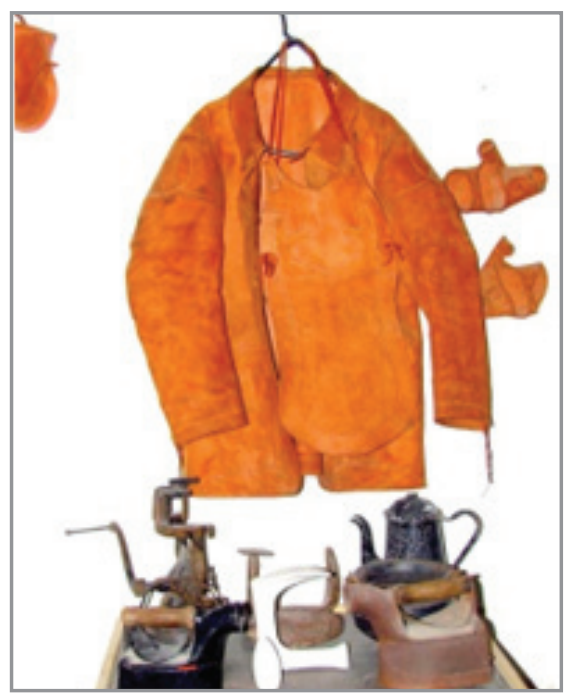

\section{Imagem 4}

Indumentária típica do vaqueiro.

Fonte: Acervo pessoal dos autores

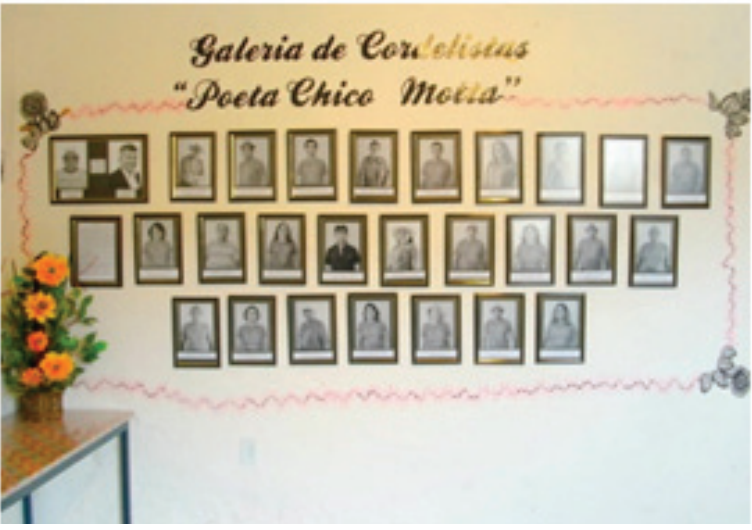

Imagem 5

Galeria dos Cordelistas de Caicó.

Fonte: Acervo pessoal dos autores

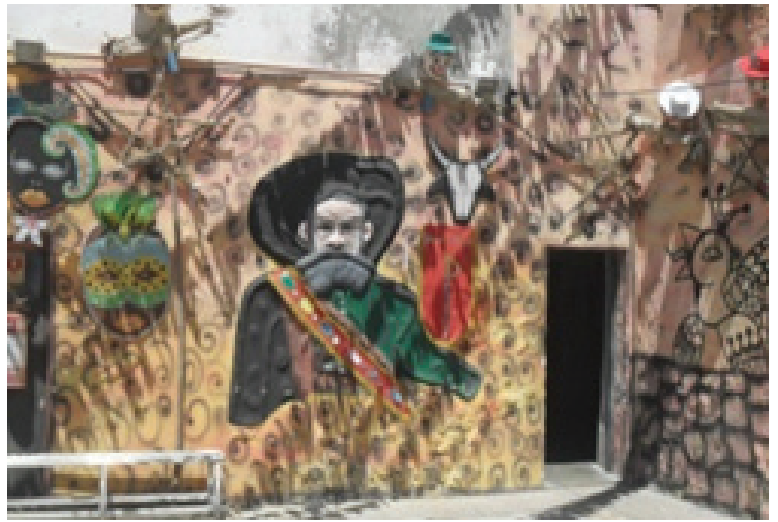

Imagem 6

Quintal com intervenção de artistas. Fonte: Acervo pessoal dos autores 
A Casa é procurada, no decorrer de todo o ano, por artistas locais e de outras regiões para realização de exposições, mostras, apresentações musicais e teatrais, lançamento de livros e atividades criativas outras. No entanto, devido aos festejos alusivos a padroeira da cidade, Sant'Ana ${ }^{1}$, é expressivo o crescimento de pessoas que a procuram, tanto para expor ou propor atividades culturais, quanto para participar de sua programação artístico/cultural.

A visitação, durante os festejos de Sant'Ana, é frequente e com um números expressivo de pessoas, de todas as formações e sem distinção religiosa ou de raça, nem limitações econômicas ou cronológicas. É perceptível ainda o contato curioso de quem se permite participar das exposições ou proposições dos artistas que colaboram com a Casa, fato que gera comentários e sensações, já que esses apelam ao toque das peças e não encontram, normalmente, restrições ou proibições para o manuseio. Fora do período de julho as visitações são menos frequentes, sendo recorrente a visita de turmas de escolares, grupos menores de alunos para pesquisa e trabalhos, bem como de visitantes aleatórios que procuram por uma boa história para contar, ou ouvir.

Por está situada nas proximidades da catedral de Sant'Ana, favorece o acesso e a circulação de pessoas, que no período das festas da padroeira da cidade, tem uma programação voltada exclusivamente para as apresentações artístico/culturais, merecendo destaque as exposições e as intervenções artísticas, dos artistas locais. Aqui destacamos o protagonismo de Lydia Brasileira e Magão, colaboradores voluntários da instituição, que provocam e realizam trabalhos no campo das Artes em Caicó e região.

\section{Na interlocução com os artistas}

Os centros culturais devem trabalhar com o foco voltado para a democratização da arte e de bens culturais, garantindo o espaço para a fruição e a expressão artística da população em geral. No mais, é importante acolher e respeitar a diversidade, entendendo que o acesso à produção cultural é um direito de todo cidadão. Para garantir a população tal direito, bem como sua participação ativa na construção da cidadania, é de suma importância que os centros contem com a colaboração de artistas, para mobilizar o cenário artístico com suas produções poéticas. Na Casa de Cultura de Caicó contamos com o protagonismo de Lydia Brasileira e Magão, artistas que com seus fazeres e concepções de arte, realizam intervenções visuais dentro e fora da edificação.

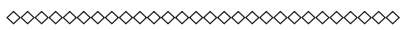

1 A centenária Festa de Sant’Ana de Caicó acontece a mais de 260 anos durante dozes dias do mês de julho, reunindo milhares de pessoas e ampliando significativamente o fluxo de residentes, turistas e visitantes que participam das festividades à Santa. A celebração é reconhecida pelo Ministério da Cultura/IFHAN como Patrimônio Imaterial, por está profundamente enraizada na história do sertão potiguar, remontando aos processos de formação da sociedade brasileira, ainda, no período da colonização portuguesa, como salienta o sítio do IFHAN http://www.iphan.gov.br 
As exposições de Lydia Brasileira proporcionam uma quebra na percepção do visitante, no que se refere ao convencional. Preocupada com a transformação de materiais e do ambiente, do ser e do ter, a artista partilha suas ideias e conhecimentos de arte e pedagogia, concebidos no decorrer do processo de ensino e de aprendizagem ao qual foi submetida, nas matrizes curriculares perpetradas na Universidade Federal do Rio Grande do Norte, onde trilhou carreira docente. Época em que mostrou sua rentabilidade, diversa aos padrões educacionais da instituição. Seus métodos de ensino já causavam um certo impacto ao convencionalismo tradicional dos fins dos anos de 1980, quando nas suas práticas pedagógicas buscava nas artes o diferencial elemento para realização dos planos pedagógicos e alcance dos seus objetivos docentes.

Já aposentada da carreira docente, Lydia Brasileira atualmente colabora por meio de o seu fazer artístico com a Casa de Cultura Popular de Caicó. A artista realiza suas exposições de concepção individual, ou em conjunto com Magão. Este, com formação autodidata, trabalhou como marceneiro, envernizador e artesão, mas encontrou no papel machê a matéria plástica ideal para suas confecções. Desenvolve atividades de instrutor de artesanato junto ao Sesc - RN e na sua hiperatividade produtiva utiliza a Casa de Cultura como abrigo para realizar trabalhos de várias formatos, principalmente bonecos e alegorias carnavalescas (Imagem 7). Seu viés artístico está completamente enlaçado ao Ala Ursa do Poço de Sant’Ana, uma troça de carnaval, conhecida na cidade como bloco do lixo.

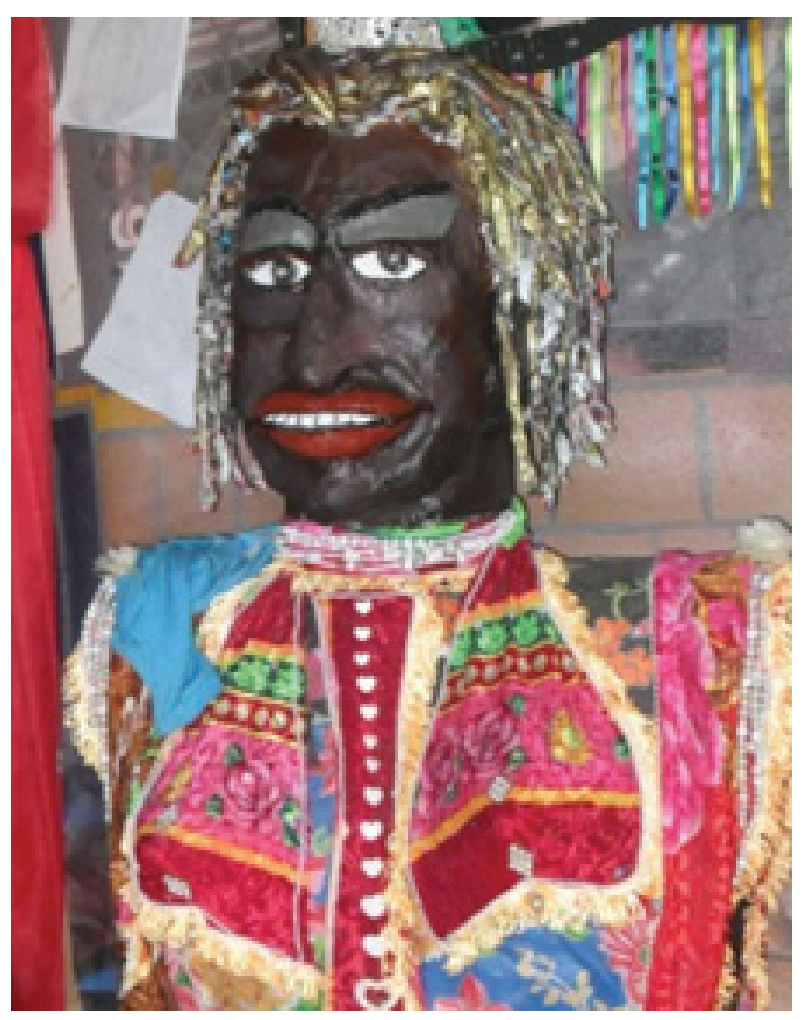

Imagem 7

Bonecos produzidos na Casa.

Fonte: Acervo pessoal dos autores. 
A grande preocupação do Magão sempre foi criar uma consciência ambiental na população jovem local e manter viva a tradição de folia de rua de Caicó. Para isso, buscou no reuso de materiais ordinários o elemento de criação dos bonecos e burrinhas, personagens alegóricos do bloco do lixo, que saem as ruas da cidade ao som de marchinhas e frevo. Há mais de vinte anos ele impulsiona o carnaval da cidade, atraindo turistas de várias regiões do Brasil que vem acompanhar o Bloco do Magão, como também é conhecido. Fora do período carnavalesco, a produção do artista pode ser exposta na Casa de Cultura ou em outros espaços expositivos da região. Todos os anos no mês de julho ele realiza uma ambientação do quintal da Casa e em dezembro monta presépios nas praças públicas do entorno. Seus trabalhos não seguem um padrão definido previamente, são construídos de modo experimental, conforme a disponibilidade de materiais para a manufatura. Na espontaneidade sua habilidade se sobrepõe e projeta uma diversidade de diálogos entre os materiais que chamam a atenção do público expectador pela originalidade, criticidade, deslocamentos de sentidos, a partir de rearranjos de objeto/ materiais ou descontinuidades no seu fazer expressivo. Tudo isso para provocar a percepção do público.

O marcante nas exposições desses caicoenses é a utilização de recursos simples para elaboração de um contexto complexo e envolvente, que fascina o expectador que a percebe, sente e aprecia seus trabalhos, fazendo-o viajar na reflexão e análise de si mesmo e do meio em que vive. Sendo assim, nos remetemos ao entendimento do norteamericano Allan Kaprow, quando este afirmou que os artistas, ao se descobrirem artistas, percebem que a vida se revela para eles como algo potente e aberto à experiência. No entendimento de Kaprow, esses descobrirão o sentido do ordinário a partir das coisas ordinárias, sem querer transformá-las em extraordinárias (KAPROW, 2006, p. 45).

Magão com sua imaginação criadora modela personagens que habitam o imaginário das pessoas, mas que também estão vivos nas estórias e lendas do lugar (Imagem 8). Seus bonecos podem ser reconhecidos personagens ou personalidades da região, que são vestidos para a grande folia (Imagem 9). Até nos seus presépios, emblemáticas imagens podem ser representadas por indivíduos que são, por vezes, considerados à margem da sociedade, mas que ganham destaque na mão do artista. Novamente recorremos aos escritos de Allan Kaprow, pois este entende que ressignificar o cotidiano e as coisas ordinárias da vida podem gerar encantamento ou horror, confusão ou admiração nas pessoas. Nessa perspectiva, Lydia Brasileira provoca na forma de apresentar suas imagens, quer pelo manifesto contra o consumo ou pela banalização do luxo, que ela mesma chama de lixo. Esses artistas seridoenses, com seus talentos, se propõem a desenvolver trabalhos no sentido de respeitar e preservar o meio ambiente, ao mesmo tempo em que tentam combater o consumo exaustivo. Eles buscam recriar o cotidiano com seus eventos corriqueiros como uma realidade estética, aproximando a criação sensível do espaço do mundo, do espaço "não-artístico". 


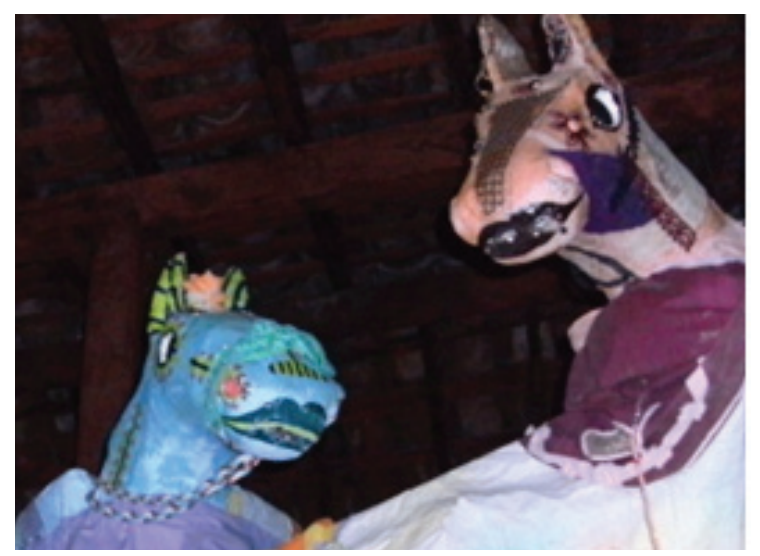

Imagem 8

Mamulengos produzidos na Casa contam as lendas do Seridó.

Fonte: Acervo pessoal dos autores.

Imagem 9

Nessa instalação, o artista criou o seu autorretrato.

Fonte: Acervo pessoal dos autores.

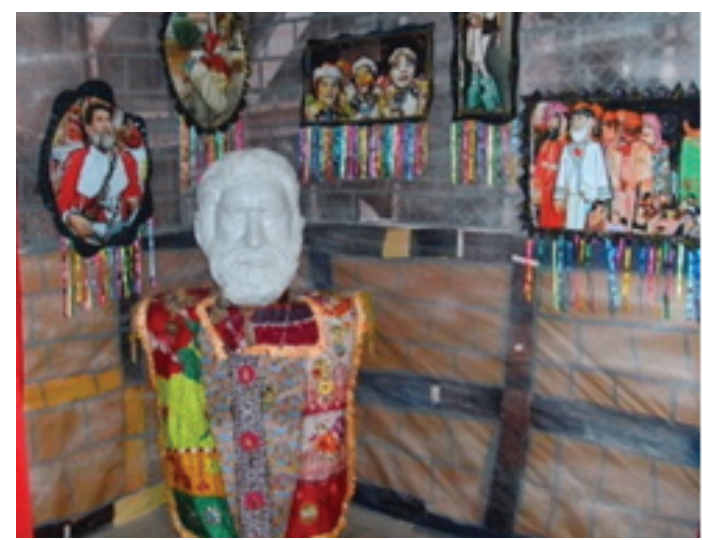

Nos festejos de Sant’Ana o que mais chama atenção na Casa de Cultura é o quintal festivo (ver imagem 4), lugar preparado para receber apresentações e que Magão sem nenhum recurso financeiro, advindo do poder público, cria um espaço cheio de signos visuais. É importante salientar que as paredes do antigo prédio já estão corroídas, mas poucos percebem as lesões provocadas pelo tempo e pela falta de restauro. Os materiais como: madeira, galhos, vidros, latas, papelão, tecido, arame e restos de tintas se associam as mãos do artista para compor um cenário desigual e latente, que perdura no quintal até a estação das chuvas. O trabalho do seridoense dialoga com o entendimento do norteamericano Kaprow, quando este salienta que os artistas, ao descobrirem o ordinário no cotidiano, buscam, por meio da arte, exprimir o seu significado real, pois a partir do nada, vão inventar o extraordinário e então é possível que inventem o nada (KAPROW, 2006, p. 45).

No ano de 2014 a coleção de bonecos e acervo de pintura do artista potiguar foi nomeada de Pinicocota do Magão, nome que satiriza a precariedade dos materiais da produção expressiva, ao mesmo tempo me que faz referência aos espaços culturais 
reservados a exposições de quadros, porém de difícil acesso aos artistas do interior do Brasil. $\mathrm{O}$ artista desenhou uma ambientação forrada de papel e tinta em três salas para disposição de quadros, pertencentes ao acervo da Casa e outros feitos em oficinas anteriormente realizadas (Imagem 10). Ele ainda montou uma instalação com novos personagens criados para serem agregados ao repertório do imaginário infantil, como um lobisomem alado que atraía de forma espantosa o público pueril (Imagem 11). Suas peças são únicas e feitas manualmente com técnicas elaboradas, fruto da experiência, perícia e necessidade. Muitas vezes elas assumem grandes proporções, ampliando a expressividade e o apelo sensorial, que provoca encantamento e fascínio no público fruidor. A espontaneidade do seu fazer artístico cotidiano, referendada pela ausência dos elaborados conceitos didáticos das academias, é potencializada pela produção de crianças e jovens que são realizadas nas oficinas e atividades diárias da Casa de Cultura (Imagem 12). Essa instalação contou uma história retirada de seu conhecimento vivenciado nas crônicas cotidianas, de um lugar cuja literatura oral prevalece sobre qualquer eventual registro escrito.
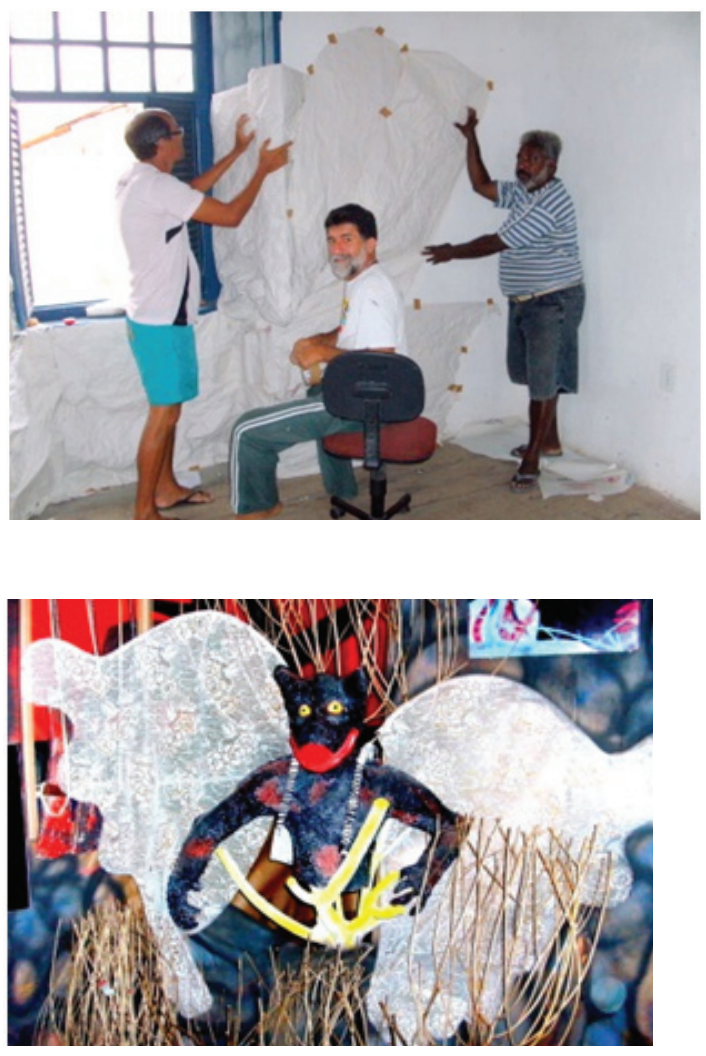

Imagem 11

Lobisomem alado.

Fonte: Acervo pessoal dos autores.

\section{Imagem 10}

Magão sentado e outros colaboradores montando exposição.

Fonte: Acervo pessoal dos autores.

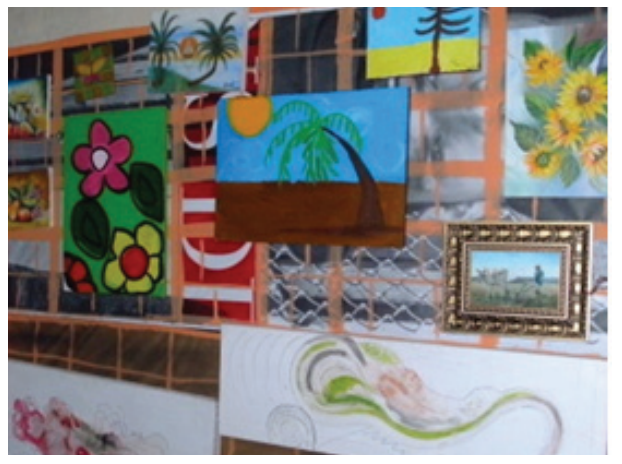

Imagem 12

Produção das oficinas de pintura.

Fonte: Acervo pessoal dos autores. 
Por outro lado, Lydia viaja nas representatividades da linguagem infantil (Imagens 13, 14 e 14), buscando a mais "pura” elaboração, em sua concepção de arte, manifestando assim o seu desejo ardente de manter o ser humano salvaguardado do massificante domínio do capital. Sua criação planejada surge de uma ideia provocada pelos acontecimentos de leituras e de seu senso critico abastecido por anos de trabalho acadêmico e pelo desejo vanguardista de rompimento e transgressão. Mesmo que utilize recursos das visualidades da educação, como recorte e colagem, o cartaz, o desenho, a pintura, o texto, seu chamamento convoca o observador ao ambiente que está inserido, para que se estabeleça um modo ativo de pertencimento. No uso desses elementos a artista acredita que as festas natalinas, carnavalescas e juninas se aproximam, borrando suas fronteiras, inclusive envolvendo as comemorações dos Festejos de Sant’Ana.

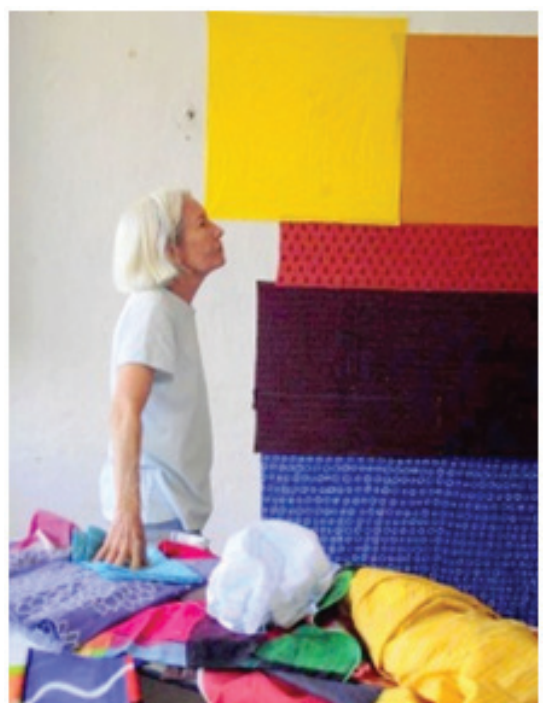

Imagem 13

Processo de montagem de instalação feita a partir

de desenhos de crianças.

Fonte: Acervo pessoal dos autores.
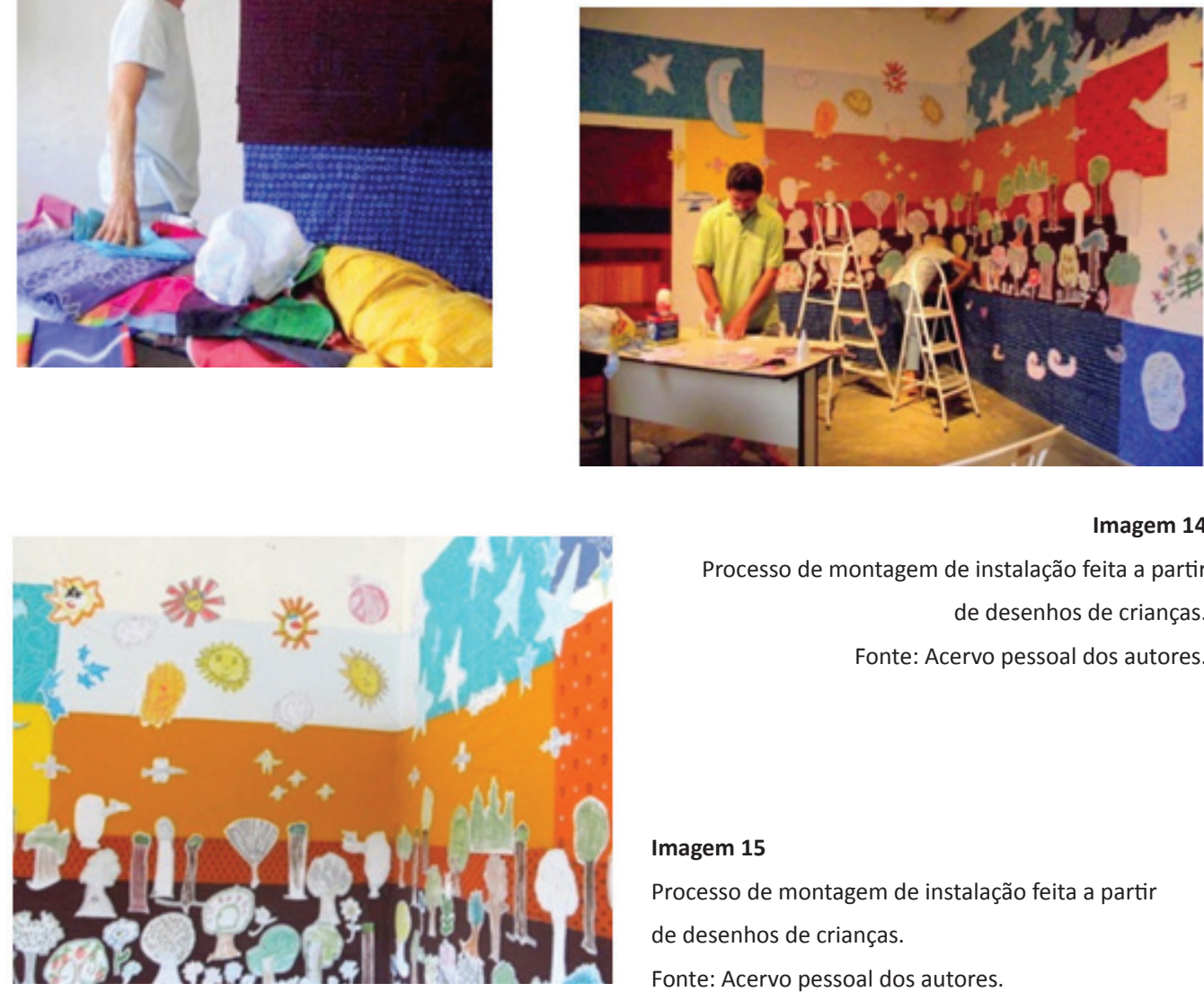

Imagem 14

Processo de montagem de instalação feita a partir de desenhos de crianças. Fonte: Acervo pessoal dos autores.

\section{Imagem 15}

Processo de montagem de instalação feita a partir de desenhos de crianças.

Fonte: Acervo pessoal dos autores. 
Uma de suas instalações na Casa de Cultura chamava-se Sonho Apocalípticos de Adão (Imagem 16). Nesse trabalho a artista mostrou um velório de serpente (o próprio Adão) rodeado de inventários representados pela árvore do bem e do mal (os saberes), o planeta capital, alegria e futebol representando três filhos de Adão (Papai Noel, Caim e Abel) e as filhas de Eva (Barbe, Suzi e Branca de Neve) que organizavam uma festa de casamento para uma princesa (Imagem 17). A narrativa da obra visual levava em consideração aspectos regionais, da culinária local e dos espaços públicos de Caicó, atrelados ao capital. Parte desse trabalho minucioso foi feito em recorte e colagem. As produções visuais da artista estão sempre rodeadas de textos denunciantes do desejo de pensar o habitante do SERtão do Seridó em harmonia com a natureza. A artista quando se apropria de desenhos infantis busca compor obras com elementos mais originais. Muitos desenhos usados por Lydia nas suas criações saem dos inúmeros grafismos infantis que ornam as paredes de sua própria residência, pois ela libera essas para servir como suporte à expressividade das crianças que a visitam.

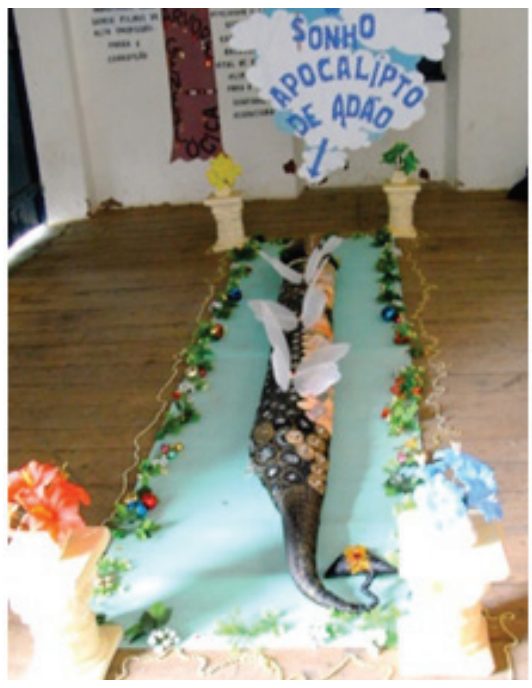

Imagem 16

O velório da serpente.

Fonte: Acervo pessoal dos autores.

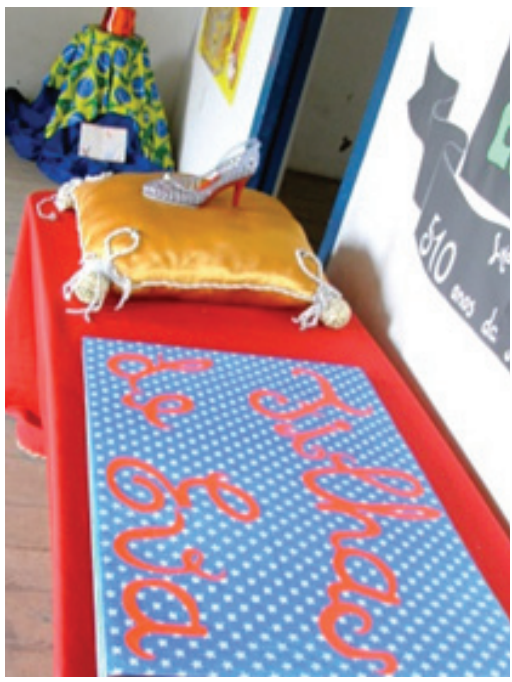

Imagem 17

O sapato da princesa, em segundo plano.de desenhos de crianças.

Fonte: Acervo pessoal dos autores.

O receptor dedicado, da obra de Lydia Brasileira, ao fruí-la capta informações contextualizadas dos seus trabalhos, que em diálogo com o repertório pessoal de cada um, é possível estabelecer relações de sentido. Contrariamente, um espírito livre ficará atraído por suas concepções lúdicas de crítica "brincalhona". Em uma de suas proposições as mensagens eram enviadas por crianças que numa série de desenhos infantis questionavam a sociedade e a escola, em relação à natureza. Lydia nos revela que suas 
experiências com as crianças a ajudaram a liberar a expressão da verdade.

Além de poder tocar e manipular muitas das obras que são expostas na Casa, as instalações dos artistas comumente evidenciam traços da cultura local, trazendo à tona o modo peculiar do fazer expressivo dos sertanejos. A arte seridoense carrega marcas que resistem à homogeneização das diferenças, negando a cultura ditatorial que impõe critérios artísticos fechados dentro do modelo eurocêntrico, pois isso acarreta em desrespeito as singularidades e a espontaneidade poética do artista, bem como da cultura do povo.

\section{Diálogos outros}

A Casa de Cultura de Caicó precisa de reforma e melhoramento de suas instalações físicas e materiais, para consequentemente implantar projetos que ofereçam bens e serviços qualificados, pois é preciso democratizar o acesso à arte e a cultura no Seridó potiguar. Procuramos dialogar com Teixeira Coelho, uma vez que tal ato segue no sentido de

[...] facilitar o acesso à produção da cultura e não à recepção de produtos culturais. Básica é a experiência de fazer, a de ver fazer é acessória. A cultura está no poético, quer dizer, no fazer, na construção; o ver releva apenas o estético, e não é por nada que se fala em coisas como 'esteticismo, 'atitude estética' diante de uma questão qualquer: são expressões que indicam estados de recepção, de passividade (COELHO, 1986, p. 68).

O estudioso paulista salienta que básica é a experiência de fazer. Sobre a noção de experiência, o pensador espanhol Jorge Larrosa Bondía nos ajuda a compreender que na contemporaneidade muitas coisas nos passam, mas poucas coisas nos acontecem de fato. É o próprio Bondia (2002, p. 21) quem assegura que, as coisas que passam na nossa vida cotidiana estão organizadas de tal forma que elas não nos provocam, ou seja, nada nos acontece. Reportando Walter Benjamin, Bondía salienta uma observação do estudioso, que tangencia a pobreza das experiências que se apresentam ao nosso cotidiano. Ele é enfático ao afirmar que "nunca se passaram tantas coisas, mas a experiência é cada vez mais rara", isso porque, "a experiência é o que nos passa, o que nos acontece, o que nos toca. Não o que se passa, não o que acontece, ou que toca” (BONDÍA, 2002, p. 21).

Entendemos aqui por sujeitos da experiência aquele que lança linhas de fuga para ampliar o campo estético no cotidiano, aventurando-se por novas práticas e fazeres, enquanto experimenta possibilidades variadas de despertar o sentir e o contato profundo com a arte, provocando estados de alma. Vivenciar experiências significativas com a arte 
pode despertar cada cidadão para a crítica e a reflexão sobre si mesmo e sobre a vida em sociedade, especialmente num mundo marcado pela aceleração, a passividade e a educação para o controle e a disciplina. Nessa perspectiva, um conjunto de ações culturais pode seguir no sentido de despertar os cidadãos para o entendimento da arte como construção, como conhecimento e como expressão (BOSI, 1986). Sendo assim, a Casa de Cultura lança linhas para instigar estímulos sensíveis, especialmente nos jovens, pois sabemos, de modo empírico, da vocação da arte e da cultura para instrumentalizar as pessoas na construção de uma consciência individual e coletiva. No mais, Ernst Fischer assegura que "A arte é necessária para que o homem se torne capaz de conhecer e mudar o mundo. Mas a arte também é necessária em virtude da magia que lhe é inerente" (FISCHER, 2002, p. 20).

Os artistas de Caicó buscam dentro da complexidade dos fazeres expressivos, apresentar suas produções no campo das artes visuais, ampliando a visibilidade das atividades criativas na região seridoense. Por sua vez, a Casa de Cultura Popular precisa garantir um espaço qualificado para a produção e difusão da cultural do município, a ampla população local, atraindo mais recursos e olhares sensíveis do poder público, para superar suas dificuldades e promover a cidadania cultural ${ }^{2}$. Deste modo, garantir o direito da população em participar das decisões políticas no campo da cultura e experimentar novas possibilidades do fazer artístico e da fruição estética. Tudo para propiciar também, condições favoráveis à formação de agentes capazes de multiplicar as ações artístico-culturais na localidade.

Os enfoques diletantes da poderosa rede de comunicação global, condicionadora do gosto pelo produto "fácil", bem como o marasmo cultural que foi submetido o Seridó, limitam, em certa medida, a produção criativa da região. Deixar de incentivar as práticas artísticas, de valorização do que é nosso, provoca o êxodo dos autores da cena cultural e isso não pode ser aceitável. Muitos artistas vão buscar novas possibilidades de sobrevivência em outras paragens, deixando lacunas prejudiciais às várias gerações que aqui permanecem.

\section{Conversa (in)conclusa}

Em Caicó, como nas demais cidades da região do Seridó-RN, são poucas as instituições públicas ou privadas que possibilitam o acesso e a produção de bens artístico-culturais, principalmente na área de Artes Visuais. Limitadas são as atividades e expo-

$\infty<\infty<\infty<\infty<\infty<\infty<\infty<\infty<\infty<\infty<\infty<$

2 De acordo com Natália Morato Fernandes, "a proposta de cidadania cultural concebe a cultura como um direito de todos os cidadãos e o Estado como agente da política cultural”. FERNANDES, N. M. A cultura como direito: reflexões acerca da cidadania cultural. In Revista Semina: Ciências Sociais e Humanas. Disponível em http://www.uel.br/revistas/uel/index.php/seminasoc/article/view/13256/13824 acesso em 20/08/2014. 
sições realizadas nos espaços existentes, fomentadoras do diálogo entre artista - obra - expectador. Diante de uma realidade de lugar que não conta com recursos privados, apenas com ínfimo investimento público, o fazer artístico em Caicó resiste e seus protagonistas rearranjam-se e resistem para conseguir manter um pequeno espaço de produção que permite a interlocução entre artistas, linguagens e público.

$\mathrm{Na}$ imensidão do sertão, distante dos grandes centros, podemos dizer que o trabalho de Lydia e Magão mantém uma comunicação provocativa, intercessora de um futuro que vislumbra as artes visuais do município. Os artistas expõem suas produções para a população, legitimando a Casa de Cultura Popular de Caicó como um espaço de criação, fruição artística e disponibilização da cultura. Enfatizamos que é fundamental aumentar os recursos, material e humano, nesse centro cultural para que ele possa acolher novos projetos e criar demandas outras, se firmando como um equipamento cultural forte, enquanto assume uma lógica de gestão que vai na contramão da lógica vigente no país, onde a arte e a cultura ainda são tratadas, na prática, ao descaso, pelo poder público.

\section{Referências bibliográficas}

BONDÍA, Jorge Larrosa. Notas sobre a experiência e o saber de experiência. In: Revista Brasileira de Educação - No 19. Campinas: ANPEd, 2002.

BOSI. Alfredo. Reflexões sobre a arte. São Paulo: Ed. Ática, 1986.

COELHO, Teixeira. A cultura e seu contrário: cultura, arte e política pós-2001. São Paulo: Iluminuras: Itaú Cultural, 2008.

. Usos da cultura: políticas de ação cultural. Rio de Janeiro: Paz e Terra, 1986.

DUARTE JUNIOR, João-Francisco. Por que Arte-Educação? Campinas: Papirus, 1991.

FERNANDES, Natália Morato. A cultura como direito: reflexões acerca da cidadania cultural. In: Revista Semina: Ciências Sociais e Humanas. Disponível em http://www.uel. br/revistas/uel/index.php/seminasoc/article/view/13256/13824 acesso em 20/08/2014.

FISCHER, Ernst. A necessidade da arte. Rio de Janeiro: Guanabara Koogan, 2002.

KAPROW, Allan. O Legado de Jackson Pollock 1952. In: Escritos de Artistas: anos 60/70. Seleção e comentários de Glória Ferreira e Cecília Cotrim. Rio de Janeiro: Zahar, 2006. 